\title{
Gottfried Semper en lengua castellana
}

\section{Antonio Armesto}

\author{
DOl: 10.5821/palimpsesto.12.3928
}

\section{$\mathrm{T}$} as una larga elaboración ha salido a la luz, en las pasadas navidades, una antología conteniendo los escritos fundamentales de Gottfried Semper (1803-1876) traduci-
al castellano desde los textos alemanes originales. ${ }^{1}$ Esta compilación contiene lo esencial del pensamiento de este arquitecto que, al obligarse a conjugar el ejercicio de su oficio con la reflexión crítica sobre él se vio comprometido en una penetrante meditación teórica sobre la naturaleza de la arquitectura y del arte. Para dar una visión comprensiva de sus ideas, junto a escritos principales como Observaciones preliminares sobre la policromía (1834), Los cuatro elementos de la arquitectura (1851), Ciencia, industria y arte (1853) y otros, esta antología incluye también una selección de la extensa obra en la que se tectura (Der Sti) de 1860 y $1863 .{ }^{2}$

Vista en perspectiva, la descomunal empresa que Semper afronta y desarrolla a lo largo de cuatro décadas -entre 1830 y 1870 aproximadamente-, constituye una indagación en profundidad sobre cuáles son las formas propias de la arquitectura, su origen, las modalidades de su combinación, y
cuáles los dinamismos que intervienen en la transformación de cuáles los dinamismos que interviene
su apariencia a través del tiempo.

En un manuscrito destinado a ser la Introducción a la tercera parte (nunca publicada) de su obra sobre el estilo en arquitectura (El estilo en las artes técnicas y tectónicas o estética práctica. Manual para técnicos, artistas y amantes del arte $)^{3}$-de la cual se publicaron los dos primeros tomos en 1860 y 1863 la expresión Der Herd und dessen Schutz (El fuego y su protección). En esa introducción, uno de sus últimos textos, proteccion). En esa introduccion, uno de sus ultimos textos,
redactado hacia 1869, intenta resumir para el futuro lector de redactado hacia 1869 , intenta resumir para el futuro lector de
ese tercer tomo, desvinculado como estaría de los otros por la distancia temporal en su edición, las líneas maestras de su teoría, desde el principio, cuando en 1834 empezó a estudiar el fenómeno de la policromía, de manera que esa breve frase sin verbómeno de la policromía, de manera que esa breve frase sin verbo puede ser
su pensamiento.

Por este motivo pensamos que esta antología podía haberse titulado así, sin más: "El fuego y su protección", porque el primer miembro del enunciado es una sinécdoque (parte por el todo) del hogar (der Herd), esto es, del lugar donde arde y se conserva el fuego domestico, mientras que el segundo conservación y, por tanto, configuran el lugar. Según Semper, estos elementos serían límites que se confeccionan a partir de lo que la naturaleza ofrece, gracias a las artes técnicas, que son destrezas humanas, es decir, conjuntos o sistemas de operaciones formales, oficios; y son tres porque este es el número de dimensiones del espacio de la experiencia, de donde proceden «los enemigos del fuego».

Esta sería, según Semper, la escena del origen de la arquitectura. Un origen lógico - vinculado a la utilidad y al trabajo humano, respaldado en la etnología- y no mítico, fabulado o idealizado. Tanto el fuego como los elementos delimitadores son formas básicas (Grundformen), originarias, motivos primordiales (Urmotiven), que poseen las dos notas propias de los arquetipos: ser concretos y universales. Aparecen primero como formas necesarias (no arbitrarias) - como las de la propia naturalezaya que se trata de formas objetivas, lo que para la arquitectura equivale a decir útiles, y luego se convierten en símbolos. Pero mientras los elementos básicos son siempre los mismos, no sucede asi con su apariencia y sus combinaciones, que cambian lugar a los diversos estilos, al estilo (Der Sti).

Aunque los cuatro elementos (Die vier Elemente) -o sea, el fuego y las tres formas del límite que lo preservannecesitan del soporte físico de la materia, el resultado de ese acto de delimitación posee, como no podía ser de otro modo, un carácter espacial, en el que lo decisivo ya no son
las sustancias materiales sino las posiciones y las distancias relativas de esos límites, por un lado, y las relaciones de contraste entre ciertos valores (cromáticos, de tonalidad, de textura, etc.), por el otro. Estos valores los adquiere la materia al ser manipulada con destreza: primero para obtener unidades de morfología alargada (hilos, cintas, barras), de dominante plana (láminas, chapas, placas, planchas) o claramente tridimensional por la equivalencia sensible de las tres dimensiones (bloques), mediante operaciones de hilado, entretejido, corte, talla, modelado, cincelado, martillado, estirado, colado, moldeado, etcétera. Después, combinando estas unidades mediante operaciones formales de entrelazado, ensamble, yuxtaposición, superposición, incrustación, etc., se confeccionan los límites.

Semper define sin ambigüedad los cuatro elementos: el primero es el fuego del hogar (der Herd), que equivale a la vida que hay que cuidar, mientras que los otros tres, que atienden a su preservación, están vinculados a la noción topológica de
delimitación: el terraplén o terraza (der Erdaufwurf), el recinto delimitación: el terraplén o terraza (der Erdaufwurf), el recinto (die Umfriedigung) y el techo (das Dach); esto es, en el mismo del suelo natural (el suelo arreglado como límite); la constricción de la extensión horizontal instaurando límites verticales y la restricción de la extensión vertical hacia lo alto con el techado como límite. Mediante la composición de estos elementos espaciales la arquitectura consigue conservar la vida
(el fuego, considerado como símbolo de sociabilidad) y orientarla, en un sitio, sirviéndose de unas técnicas.

El modelo reducido de una cabaña del Caribe, que encuentra en la Gran Exposición de Londres (1851), le sirve a Semper de caso ilustrativo, un epítome que contiene la evidencia de los cuatro elementos definidos por él y sus relaciones. Allí está el fuego protegido por los tres límites y estos se muestran por separado, analíticamente: la terraza como plano elevado o suelo arreglado y preparado para recibir al hogar (operación estereotómica de modelado, tridimensional); el techo que cubre, apoyado en sus propios soportes (operación de carpintero, tectónica); el recinto que circunda el espacio (confeccionado a partir de las artes textiles como la cestería y los tapices), pero que no sive de apoyo al techo.

Puesto que la arquitectura, según se ha visto, resulta de arte de delimitar el espacio y para ello se sirve de las artes técnicas o artesanías (las artes textiles, la cerámica, carpintería o tectónica, la estereotomía y la metalotecnia), el estilo, según Semper, dependería en gran parte de las formas derivadas de estas destrezas, aunque también de servir, las instituciones sociales, de poder o de culto, etc.

Pero, según él mismo explica, la cabaña de cañas de bambú entrelazadas, no es aún verdadera arquitectura sino su precedente. No lo es porque la verdadera arquitectura debe ser monumental, es decir, perdurable, de piedra y, a partir de ahí, recibir el adecuado tratamiento artístico para que se ajuste a la idea a la que debe servir y así se convierta en imagen de aquello que por sí mismo no tiene imagen: de estado de civilización, de las instituciones colectivas, etc. ". En este proceso residiría la explicación del fenómeno de la policromía y en ge
en arquitectura.

Es en este punto donde, a nuestro juicio, la imaginación teórica de Semper alcanza sus cotas más altas porque e tratamiento artístico no consiste en superponer linealmente la decoración a la construcción sino en conseguir que se produzca una metamorfosis, una transmutación (Stoffwechsel) tanto del material como de las artes técnicas, es decir, que ambos experimenten un proceso de pseudomorfía de la forma constructiva y útil a la forma bella. Por este procedimiento el monumento en piedra tallada y perdurable, a través de la policromía y el revestimiento puede perdurable, a través de la policromía y el revestimiento puede producir una intensa evocación de los motivos primordiales, papel fundacional. ${ }^{4}$ Así la tienda nómada adornada del tabernáculo se transmutó en el dorado templo de Salomón tabernáculo se transmutó en el dorado templo de Salomón; el templo egipcio recogió los motivos del previo mercado propiedades milagrosas; las tumbas licias talladas en piedra y decoradas evocan las arcas funerarias cubiertas con ricos y coloridos tapices, apoyadas sobre parihuelas y destinadas a ser incineradas; algo parecido a lo que sucedió con el templo griego de piedra policromada, cuyo origen habría que buscarlo, no en una cabaña de madera, como decía Vitruvio, sino más bien en los muebles domésticos, como son los arcones apoyados sobre un armazón tectónico: veces, el cofre del tesoro un templo".

Lo que movilizó a Semper a emprender aquella colosal tarea fue el hecho de constatar la decadencia de la arquitectura y del arte de su época, su desorientación, confusión y arbitrariedad, resultado de su alejamiento y olvido de los motivos primordiales, en los que radica la base objetiva de las formas propias de la arquitectura y su carácter como arte autónomo. Su crítica al eclecticismo tiene un acento casi sistemático y dispara en todas direcciones: ataca los materialistas "influidos por las ciencias naturales y las matemáticas" pues en ellos "la materia se impone a la idea, condicionando de manera férrea el mundo de las formas arquitectónicas hasta hacerlas derivar exclusivamente del material"; y porque "ven en la mera construcción la esencia de la arquitectura, con lo que se alejan casi por completo de su auténtico fin"; a los historicistas, tanto a los neogriegos como a los neogóticos, "influidos por la historia del arte y la investigación sobre lo antiguo"; a los puristas, esquemáticos y futuristas "influidos por la filosofía especulativa"..Los impresionantes cambios que se estaban operando en impresionantes cambios que se estaban operando en tócn los ordenes, en especial en el ámbito del progreso de que contribuirán a acabar con aquella arbitrariedad y de que contribuirán a acabar con aquella arbitrariedad y
decadencia, pero al mismo tiempo le dejan inerme respecto decadencia, pero al mismo tiempo le dejan inerme respecto
a la dirección que la arquitectura y el arte pueden tomar en a la dirección que la
el futuro inmediato.

Aunque han pasado 180 años desde la fecha del texto más antiguo que se recoge en esta antología, la tentación de establecer algunos paralelismos entre nuestro presente y aquel momento es muy fuerte. En todo caso, parece fundamental en arquitectura apareciera en el programa de la última Bienal de Venecia (2014) elaborado por una figura

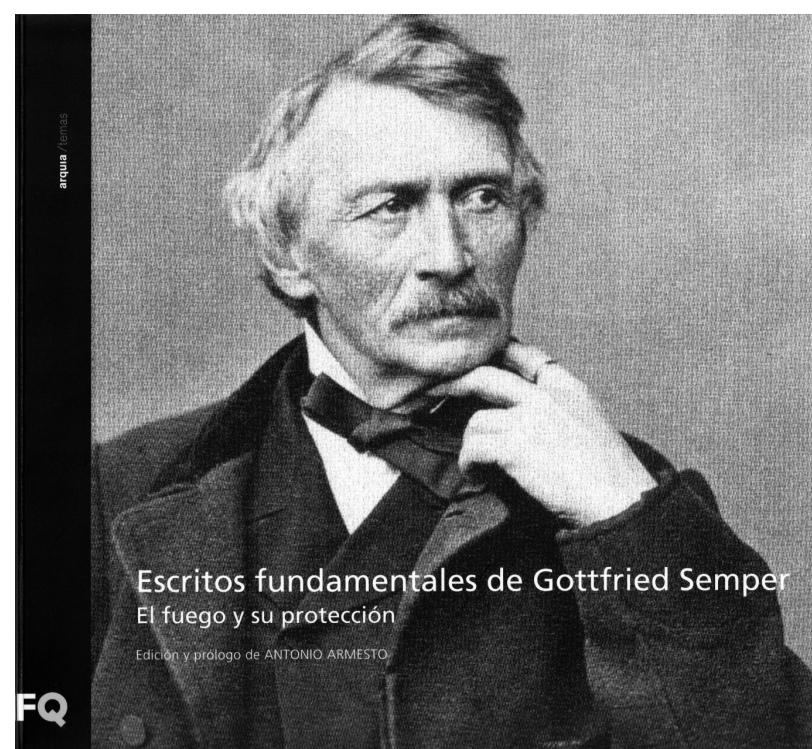

muy respetada de la arquitectura contemporánea, el holandés Rem Koolhas, a través del título de una de las exposiciones centrales: Elements of Architecture. En ella el elenco de los elementos ascendía a quince, incluyendo los cuatro de Semper. A algunos nos pareció llamativa la presencia otra vez de elementos a lo Durand, y tros de carácter "tecnológico" que dejaban, al salir, la sensación de haber visitado una de esas ferias de la construcción, porque ya Semper hizo en su momento, con mucho respeto, la crítica a las contribuciones de Durand y Rondelet a una teoría de la arquitectura, por considerarlas insuficientes, esquemáticas o parciales. De todos modos, para quien esté convencido de que la arquitectura progresa, la victoria del presente sobre el pasado le parecerá bien clara en Venecia: Koolhaas 15, Semper 4.

Nos gustaría meditarlo con calma, pero tenemos la sospecha de que, en cuestión de elementos básicos, no gana el que encuentra más.

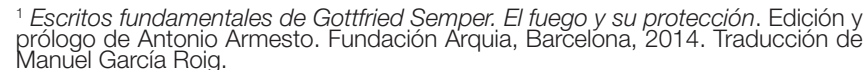

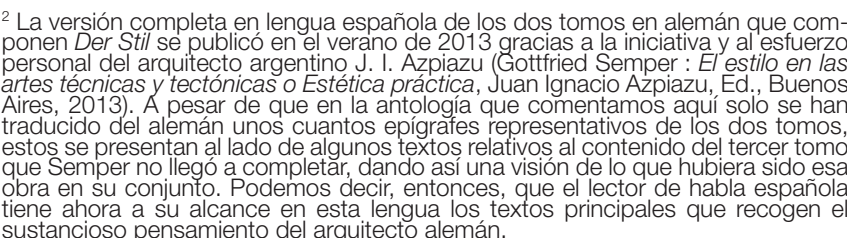

Der Stiti in den technischen und tektonischen Künsten, oder Praktische Aesthetik.
Ein Handouch tur Techniker, Künstler und Kunstrfeunde.

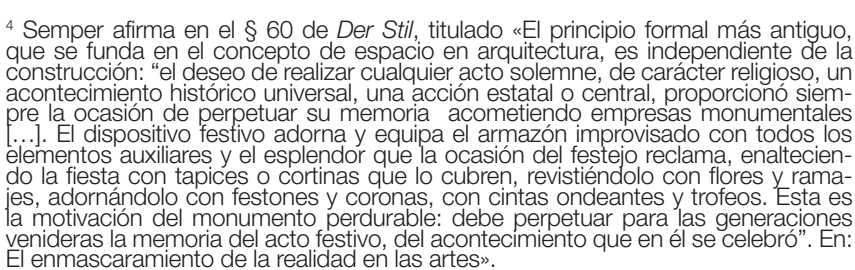

ABSTRACT A finales de 2 de Gotttried Semper. El fuego y su protección (Edición y y prólogo de Antoni
Ammesto. Fundación Arquia, Barcelona, 2014. Traducción de Manuel García
Roig), que contiene los principales escritos de Semper (1803-1876), incluida
una selección de fragmentos de su obra más extensa, Der Stil, traducidos por una selección de fragmentos de su obra más extensa, Der Stil, traducidos por
primera vez al castellano desde los originales en alemán. Entre otros, se hallan: Observaciones preliminares sobre la policromia (1834), Los cuatro elementos de la arquitectura (1851) y Ciencia, industria y arte (1853).

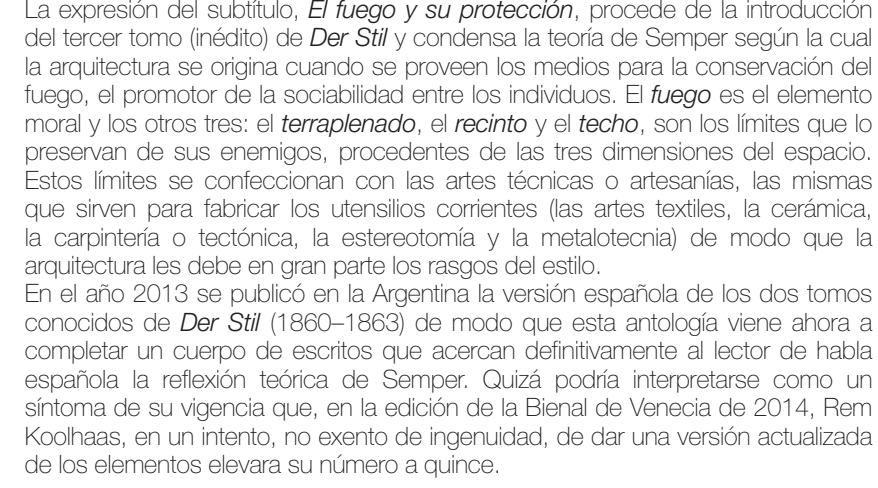

Palabras clave: Semper, fuego, Der Stil.

Antonio Armesto es Doctor arquitecto y profesor titular de Departamento de Proyectos Arquitectónicos de la Universitat Politècnica de Catalunya. 